\title{
Contexto de trabalho e custo humano no trabalho em um órgão do poder judiciário brasileiro
}

\author{
Work context and the human cost of work \\ in a Brazilian judiciary organ
}

\author{
Carla Sabrina Antloga ${ }^{1}$ \\ Marina Maia ${ }^{1}$ \\ Kamilla Rocha Cunha ${ }^{1}$ \\ Juliana Peixoto ${ }^{1}$
}

${ }^{1}$ Departamento de Psicologia Social e do Trabalho, Instituto de Psicologia, Universidade de Brasília. Campus Universitário Darcy Ribeiro, Instituto de Psicologia/Sala A1 073/4, Asa Norte. 70910 900 Brasília DF Brasil. antlogacarla@gmail.com

\begin{abstract}
In recent years, in order to ensure the effectiveness of justice, the process of reform of the Brazilian Judiciary began. If, on the one hand, the changes have been significant and positive, on the other, little is known about the impact of the changes on the worker. In order to give visibility to the effects of these changes, based on the theory of the ergonomics of the activity, the scope of this research was to evaluate the Work Context and the Human Cost of Work in a Brazilian Judiciary Organ. The Assessment Scale of Work Context (ASWC) and the Scale of Human Cost of Work (SHCW) were used, as they are both components of the Inventory on Work and Risk - IWR. The study included 383 staff in different locations: $58 \%$ female, $62.7 \%$ with postgraduate qualifications, 59.3\% married and 53\% between 21 and 40 years of age. The results in ASWC reveal critical factors in work organization and socio-professional relations. In the case of SHCW, Affective Cost and Cognitive Cost factor assessments were moderate to critical. The ANOVA revealed differences in perceptions related to some socio-demographic variables.

Key words Judiciary organ, Ergonomics of the activity, Human cost of work, Work context, Work organization, Socio-professional relationships
\end{abstract}

Resumo Nos últimos anos, visando a garantir a efetividade da justiça, iniciou-se o processo de reforma do judiciário brasileiro. Se, por um lado, as mudanças têm sido significativas e positivas, por outro pouco se sabe dos impactos das transformações sobre o trabalhador. A fim de dar visibilidade aos efeitos destas transformações, com base no referencial teórico da ergonomia da atividade, o objetivo desta pesquisa foi avaliar o Contexto de Trabalho e o Custo Humano no Trabalho em um órgão do Poder Judiciário brasileiro. Utilizaramse a Escala de Avaliação do Contexto de Trabalho (EACT) e a Escala de Custo Humano no Trabalho (ECHT), ambas componentes do Inventário sobre Trabalho e Risco de Adoecimento (ITRA). Participaram deste estudo 383 servidores de diferentes lotações, sendo $58 \%$ do sexo feminino, $62,7 \%$ com curso de pós-graduação completo, 59,3\% casados e 53\% com idade entre 21 e 40 anos. Os resultados apontam, na EACT, para avaliações tendendo a críticas nos fatores Organização do Trabalho e Relações Socioprofissionais. No caso da ECHT, os fatores Custo Afetivo e Custo Cognitivo tiveram avaliação de moderada a crítica. A ANOVA evidenciou diferenças de percepções relacionadas a algumas variáveis sociodemográficas.

Palavras-chave Poder judiciário, Ergonomia da atividade, Custo humano no trabalho, Contexto do trabalho, Organização do trabalho e relações socioprofissionais 


\section{Introdução}

Ao longo dos últimos 30 anos, trabalhadores e organizações experimentaram mudanças importantes nas formas de trabalho, nas exigências quanto à qualidade e produtividade, bem como nas relações com consumidores e usuários-cidadãos, que impactaram na saúde do trabalhador e na efetividade organizacional ${ }^{1-3}$. Tais transformações manifestaram-se mais radicalmente após a reestruturação produtiva da década de $1970^{4} \mathrm{e}$ da inserção das novas tecnologias de informação e comunicação ${ }^{5}$.

Uma combinação de diversos fatores advindos da revolução tecnológica, da crise do petróleo e do esgotamento do modelo de produção capitalista baseado no binômio taylorismo/fordismo culminaram no nascimento da reestruturação produtiva. Esta buscou alinhar o perfil das organizações produtivas, as relações de produção, o modelo de gestão do trabalho e da tecnologia, o papel dos estados nacionais e o quadro jurídico internacional ${ }^{4}$.

As novas tecnologias configuram-se como um dos elementos da reestruturação produtiva. Promovendo a informatização de sistemas produtivos, trouxeram benefícios inequívocos para a celeridade dos processos de trabalho ${ }^{6}$. Todavia, ao passo que se verificam benefícios, pesquisas na área das ciências do trabalho têm apontado para as consequências para os trabalhadores, que nem sempre são positivas? ${ }^{7}$.

No campo desta pesquisa, o Poder Judiciário, verifica-se que o processo de reforma e modernização promulgado pela Emenda Constitucional $\mathrm{n}^{\circ} 45$, de oito de dezembro de 2004, atrelado ao Processo Judicial eletrônico (PJe) e a busca pelo cumprimento das metas nacionais do Conselho Nacional de Justiça (CNJ) envolveu inovações tecnológicas e mudanças no contexto de produção que impactaram negativamente na saúde e no bem-estar dos trabalhadores. Estudos ilustram os impactos das novas exigências ao evidenciarem que os trabalhadores do poder judiciário estão submetidos a um volume cumulativo de tarefas e a sobrecarga de trabalho, a falta de autonomia e a priorização da quantidade de julgados em detrimento da qualidade ${ }^{8-10}$.

O Poder Judiciário Brasileiro é composto pelo Supremo Tribunal Federal, pelo Conselho Nacional de Justiça, Superior Tribunal de Justiça, Tribunais Regionais Federais e Juízes Federais, Tribunais e Juízes do Trabalho, Tribunais e Juízes Eleitorais, Tribunais e Juízes Militares e Tribunais e Juízes dos Estados e do Distrito Federal e Terri- tórios ${ }^{11}$. Tem por objetivo preservar os princípios da legalidade e da igualdade, harmonizando as relações sociais e exercendo o controle social para garantir o respeito às leis ${ }^{11}$. Pelo sistema constitucional brasileiro, cabe ao Judiciário o controle jurisdicional do executivo, do legislativo e do ministério público ${ }^{12}$.

Ao longo dos últimos 10 anos, o Poder Judiciário sofreu grandes modificações em sua estrutura e nos seus processos de trabalho. Tais transformações seguem o curso das metamorfoses observadas no mundo do trabalho como um todo, especialmente, deu-se em avanços e recuos, como ressalta Andrade ${ }^{8}$. Um exemplo é criação de novos órgãos, que em seguida foram extintos, mas posteriormente voltaram à ativa e foram reintegrados ao poder, como aponta Tavares ${ }^{13}$.

As grandes dificuldades existentes, especialmente a morosidade e as deficiências na aplicação da Justiçą ${ }^{14}$, levaram os cidadãos brasileiros a se declararem insatisfeitos com a Justiça do nosso país ${ }^{15}$. Visando solucionar esses problemas, foi proposta uma reforma que tornasse os processos judiciais mais rápidos, de forma a satisfazer o seu principal cliente, a população brasileira. Todas essas transformações influenciaram a visão dos cidadãos sobre o Judiciário.

A Reforma do Judiciário, tema que tem ocupado grande parte da mídia jornalística nos últimos anos e suscitado discussões infindáveis sobre seu papel e efetividade, foi estabelecida sob o argumento de solucionar a lentidão dos processos judiciais e aumentar a eficácia de suas decisões. Assim, a Câmara dos Deputados e o Senado Federal promulgaram a Emenda Constitucional $\mathrm{n}^{\circ} 45$, de 8 de dezembro de 2004, o que impulsionou a reforma e a modernização do Judiciário ${ }^{8}$.

As inovações advindas da reforma do judiciário geraram mudanças na organização do trabalho. Por exemplo, hoje os trabalhadores gerenciam um volume muito maior de informação por unidade de tempo ${ }^{11}$. A busca por maior agilidade na prestação jurisdicional ${ }^{16}$, apesar de seus impactos positivos, acirrou algumas contradições. Exemplo disso é a carência de tempo para treinamento dos servidores para lidarem com as novas tecnologias e processos, bem como o tempo exíguo para adaptação dos trabalhadores em suas novas atividades, principalmente quando considerado que haverá intensificação do trabalho.

Ferro $^{17}$ estudou a motivação dos servidores da Justiça Federal. Verificou-se que, de modo geral, o nível de insatisfação dos servidores é baixo, e o de satisfação é alto. No estudo de Wirth ${ }^{18}$, investigaram-se as vivências de prazer e sofrimento 
em um órgão do Poder Judiciário Federal. Foram apontados como fatores de prazer no trabalho: realização profissional; ver as coisas acontecerem; ver a satisfação alheia; lidar com pessoas; ter um bom ambiente de trabalho; ter boas relações; ver a cooperação entre as pessoas; e obter sua confiança, seu afeto, seu reconhecimento e sua aprovação. As fontes de sofrimento no trabalho foram: o engessamento da organização de trabalho; o estresse atrelado à pressão e aos momentos difíceis; e, a dificuldade de lidar com a diversidade de pessoas.

Em uma investigação relativa às mudanças estruturais e administrativas implantadas na coordenadoria de taquigrafia de um órgão do Poder Judiciário Federal e as vivências de prazer e sofrimento decorrentes desse processo ${ }^{19}$, verificou-se que o prazer no trabalho está relacionado à possibilidade de realização material e profissional e à estabilidade oferecida pelo setor público, além do orgulho por atuar em uma instituição que goza de boa reputação perante a sociedade. Já o sofrimento no trabalho está relacionado à organização e à forma como foram implementadas as mudanças.

No intuito de explorar a questão da saúde do trabalhador do poder judiciário, este estudo tem como referencial teórico a ergonomia da atividade. O pressuposto da Ergonomia da Atividade é a adaptação do trabalho ao ser humano, contrariando, assim, a pretensão de importante volume das propostas existentes nas ciências do trabalho, que propõem a adaptação do homem ao seu contexto ${ }^{20}$. Conforme Ferreira e Mendes ${ }^{21}$, o principal objetivo é a compreensão dos indicadores críticos presentes no contexto de trabalho e das estratégias individuais e coletivas de mediação que os indivíduos constroem para responder às múltiplas exigências existentes nas situações de trabalho.

A Ergonomia da Atividade postula que as atividades de trabalho se dão em um Contexto de Produção de Bens e Serviços (CPBS), o qual compreende as condições de trabalho (contexto material), a organização do trabalho (contexto organizacional) e relações socioprofissionais (contexto social). No CPBS é que se operam as Estratégias de Mediação Individuais e Coletivas (EMIC), utilizadas pelos trabalhadores para lidar com o Custo Humano do Trabalho (CHT). Este se refere ao que os trabalhadores despendem física, cognitiva e afetivamente para dar conta das exigências das tarefas ${ }^{22}$.

Em uma situação real de trabalho, o trabalhador é demandado a realizar um conjunto de tarefas prescritas pela organização, porém, as atividades realizadas efetivamente nem sempre consistem do proposto ${ }^{23}$. Dessa forma, diante das contradições entre o prescrito e o real, o trabalhador elabora estratégias para atender as exigências do CPBS e isso implica em um $\mathrm{CHT}^{24}$. Quando as estratégias de mediação são eficazes, há vivências de bem-estar no trabalho. Por outro lado, se as estratégias de mediação falham, há risco de adoecimento.

Neste estudo foi utilizado o Inventário de Trabalho e Riscos de Adoecimento (ITRA). Ferreira e Mendes ${ }^{21}$ realizaram o primeiro estudo com este instrumento quando foi construído e validado com uma amostra de 1916 auditores da previdência social. Em Mendes ${ }^{25}$, há quatro pesquisas que fizeram uso do ITRA ${ }^{26-29}$. Nesses estudos, com amostras diversas: digitadores terceirizados de uma instituição bancária, carteiros, bancários e líderes religiosos de organizações pentecostais, verificou-se que há rigidez das normas e da forma como a atividade deve ser realizada, bem como sobrecarga de trabalho. Aparentemente há, por parte dos trabalhadores, o desenvolvimento de estratégias de mediação que garantem a execução das tarefas e minimizam o risco de sofrimento.

Em outra pesquisa, com policiais civis, realizado por Anchieta et al. ${ }^{30}$, concluiu-se que, apesar de não terem sido identificados problemas graves relacionados à saúde do policial, é necessário analisar a organização do trabalho para que não haja falhas nas estratégias de mediação. A pesquisa de Shimizu e Carvalho Júnior ${ }^{31}$, com trabalhadores da Estratégia Saúde da Família do Distrito Federal (ESF-DF), evidenciou uma situação de trabalho caracterizada pela divisão excessiva das tarefas, condições de trabalho precárias e elevada exigência de cuidado que promovem vivências de sofrimento para esses trabalhadores. As pesquisas apresentadas mostram a utilização do ITRA em categorias profissionais diversas. Nesse sentido, o poder judiciário é um campo profícuo para a ampliação do conhecimento acerca do trabalho e dos riscos de adoecimento.

Com base no exposto, o objetivo desta pesquisa foi avaliar o Contexto de Trabalho e o Custo Humano no Trabalho em um órgão do Poder Judiciário brasileiro.

\section{Método}

A pesquisa foi realizada em um órgão do poder judiciário brasileiro com sede em Brasília. No 
momento da pesquisa, a organização contava com 2.600 servidores distribuídos em 25 áreas.

A demanda pela pesquisa partiu do serviço de saúde da organização, que havia identificado, nos dois anos anteriores ao estudo, um aumento expressivo nos casos de adoecimentos e afastamentos nas classificações CID-F (transtornos mentais e do comportamento) e CID-M (doenças do sistema osteomuscular e do tecido conjuntivo). Somado a este fator, a demanda pelo serviço de fisioterapia e pelo serviço de psicologia do órgão também passou por um incremento significativo.

\section{Participantes}

Participaram deste estudo 383 servidores de diferentes lotações. Essa amostra corresponde a $14,73 \%$ do total de trabalhadores da organização no momento da pesquisa. Tal número, em um cálculo de erro amostral de 5\% (para amostra aleatória) mostrou-se adequado.

Dos respondentes, $58 \%$ são do sexo feminino, $62,7 \%$ possuem curso de pós-graduação completo, $59,3 \%$ são casados e $53 \%$ têm idade entre 21 e 40 anos. A média de tempo de serviço na instituição é de 10,40 anos ( $\mathrm{DP}=8,43)$, sendo que $42,4 \%$ da amostra têm entre 1 a 10 anos. Quanto ao tempo de serviço na lotação atual, a média é de $8,15(\mathrm{DP}=7,71)$ com $51,5 \%$ possuindo até cinco anos. Dentre os participantes, 38,6\% afirmaram já ter se afastado do trabalho pelo menos uma vez por motivo de saúde.

\section{Instrumentos}

Neste estudo foi utilizado um questionário contendo a Escala de Avaliação do Contexto de Trabalho (EACT) e a Escala de Custo Humano no Trabalho (ECHT). Ambas compõem o Inventário sobre Trabalho e Risco de Adoecimento (ITRA) ${ }^{32}$. O ITRA foi criado e validado por Ferreira e Mendes $^{21}$ em uma pesquisa nacional. Posteriormente, foi adaptado, revalidado e publicado por Ferreira et al. ${ }^{33}$ e, em 2006 passou por uma nova validação devido a alguns ajustes. É composto por quatro escalas, sendo elas: Escala de Avaliação do Contexto de Trabalho (EACT), Escala de Custo Humano no Trabalho (ECHT), Escala de Indicadores de Prazer e Sofrimento no Trabalho (EIPST) e Escala de Avaliação dos Danos Relacionados ao Trabalho (EADRT). Em função do objetivo desta pesquisa, foram utilizadas apenas as duas primeiras escalas.

A EACT é composta por 30 itens associados a uma escala de resposta tipo Likert de cinco pontos de frequência, variando de 1 (nunca) a 5 (sempre). Os itens avaliam a Organização do Trabalho, as Condições de Trabalho e as Relações Socioprofissionais dos trabalhadores. A ECHT é composta por 32 itens associados a uma escala de resposta tipo Likert de cinco pontos, variando de 1 (nada exigido) a 5 (totalmente exigido). Os itens mensuram o Custo Físico (10 itens), o Custo Cognitivo (10 itens) e o Custo Afetivo (12 itens). A descrição dos fatores e os índices psicométricos ${ }^{32}$ são apresentados a seguir:

$\checkmark \quad$ Fator Organização do Trabalho ( $\alpha=$ 0,72 ): Expressa "a divisão e conteúdo das tarefas, normas, controles e ritmos de trabalho".

$\checkmark \quad$ Fator Condições de trabalho $(\alpha=0,89)$ : Expressa "a qualidade do ambiente físico, posto de trabalho, equipamentos e material disponibilizados para a execução do trabalho”.

Fator Relações Socioprofissionais $(\alpha=$ $0,87)$ : Expressa "os modos de gestão do trabalho, comunicação e interação profissional".

$\checkmark \quad$ Fator Custo Físico $(\alpha=0,91)$ : Expressa o "dispêndio fisiológico e biomecânico imposto ao trabalhador pelas características do contexto de produção”.

$\checkmark \quad$ Fator Custo Cognitivo $(\alpha=0,86)$ : Expressa o "dispêndio intelectual para aprendizagem, resolução de problemas e tomada de decisão no trabalho".

$\checkmark \quad$ Fator Custo Afetivo $(\alpha=0,84)$ : Expressa o "dispêndio emocional sob a forma de reações afetivas, sentimentos e de estados de humor".

Ao final do questionário, foi solicitado ao participante que respondesse a alguns dados sociodemográficos: sexo, idade, escolaridade, estado civil, tempo de serviço na organização e tempo de serviço na lotação atual.

\section{Procedimentos}

Para dar início à pesquisa, primeiramente realizou-se uma reunião com os servidores da área de saúde da organização para estabelecimento das estratégias de sensibilização. Desse modo, a sensibilização ocorreu por meio de chamadas na intranet do órgão explicando os objetivos da pesquisa, a sua importância e convidando os trabalhadores para respondê-la. O questionário ficou hospedado na ferramenta Google Drive que permite a construção eletrônica de questionários em geral. O link para as escalas foi disponibilizado na intranet da organização. Os servidores entravam com sua matrícula e, ao lado direito de seu monitor, havia um convite para participação, com o link que o direcionaria para a página, que 
"piscava” na tela. Se ele não desejasse responder, poderia ignorar o convite que, no entanto era feito, novamente, caso saísse e entrasse posteriormente. $\mathrm{O}$ instrumento ficou disponível para os respondentes durante 41 dias.

\section{Análise dos dados}

Os dados dos questionários foram tabulados e analisados no software PASW, versão 18.0. Foi realizada uma inspeção para que fossem verificados erros de digitação e dados faltosos. Foram geradas estatísticas descritivas (média e desvio padrão) para cada um dos fatores das escalas utilizadas na pesquisa. Os valores das médias são classificados com base em três níveis, conforme apresentado na Tabela 1. Para comparar as médias das variáveis sociodemográficas relacionadas aos fatores das escalas, foi realizada ANOVA.

\section{Resultados}

Esta seção está dividida por escala para melhor compreensão.

\section{Avaliação do Contexto de Trabalho}

A Escala de Avaliação do Contexto de Trabalho (EACT) é composta pelos fatores: organização do trabalho, relações socioprofissionais e condições de trabalho. A Tabela 2 apresenta as médias, os desvios-padrão e a variância de cada um dos fatores no estudo realizado.

A média do fator Organização do Trabalho foi de 3,25 situando-se na faixa de avaliação

Tabela 1. Níveis e avaliação da EACT e da ECHT.

\begin{tabular}{ll}
\hline \multicolumn{1}{c}{ Níveis } & \multicolumn{1}{c}{ Avaliação } \\
\hline Acima de 3,7 & Avaliação mais negativa, grave \\
Entre 2,3 e 3,69 & Avaliação mais moderada, crítico \\
Abaixo de 2,29 & Avaliação mais positiva, satisfatório
\end{tabular}

Tabela 2. Fatores da Escala de Avaliação de Contexto de Trabalho.

\begin{tabular}{lccc}
\hline \multicolumn{1}{c}{ Fator } & Média & DP & Variância \\
\hline Organização do Trabalho & 3,25 & 0,63 & 0,79 \\
Relações Socioprofissionais & 2,47 & 0,79 & 0,89 \\
Condições de Trabalho & 2,07 & 0,85 & 0,92 \\
\hline
\end{tabular}

“moderada à crítica”. Essa dimensão inclui itens como: "o ritmo de trabalho é excessivo", "as tarefas são cumpridas sob pressão de prazos", "existe forte cobrança por resultados". O item "existe fiscalização do desempenho" ( $\mathrm{M}=3,78$; $\mathrm{DP}=1,05$; Variância $=0,79$ ) recebeu avaliação "negativa a grave".

No fator Relações Socioprofissionais verificou-se uma avaliação de "moderada a crítica" $(\mathrm{M}=2,47 ; \mathrm{DP}=0,79$; Variância 0,89$)$. Os itens que apresentaram uma avaliação de "moderada a crítica” neste fator foram: "A comunicação dos funcionários é insatisfatória”, "Falta integração no ambiente de trabalho", "Existem disputas profissionais no local de trabalho", "Os funcionários são excluídos das decisões", "A distribuição de tarefas é injusta", "A autonomia é inexistente".

A média do fator Condições de Trabalho foi de 2,07 ficando localizada na faixa de avaliação "mais positiva e satisfatória" $(\mathrm{M}=2,07$; $\mathrm{DP}=$ 2,07; Variância $=0,92)$. Itens como "as condições de trabalho são precárias”, “o ambiente físico é desconfortável", "existe muito barulho no ambiente de trabalho" compõem esse fator. Nenhum dos itens foi avaliado de forma mais negativa.

O valor de variância nos três fatores indica pouca dispersão em torno da média, o que pode significar certo consenso na percepção dos trabalhadores acerca do contexto de trabalho.

Os resultados descritivos de média e desvio - padrão divididos pelas variáveis sociodemográficas do estudo são apresentados na Tabela 3. O procedimento de Análise de Variância (ANOVA) foi realizado para verificar se haviam diferenças de percepção dos fatores da escala quanto às categorias sexo, escolaridade, estado civil, faixa-etária, tempo de serviço no cargo, tempo de serviço na lotação e afastamento por motivo de saúde relacionado ao trabalho.

A análise de variância de um fator mostrou que não há diferenças significativas entre sexo, estado civil, faixa etária e tempo de serviço na lotação na avaliação dos fatores da EACT. De forma global, quando comparadas as médias das variáveis sociodemográficas citadas, os participantes do estudo apresentam percepções similares do contexto de trabalho.

Com relação à escolaridade, houve diferença significativa de percepção no fator organização do trabalho $[\mathrm{F}(2,381)=3,114 ; \mathrm{p}=0,046]$. Neste fator, os participantes da pesquisa, dependendo da sua escolaridade, diferem quanto à avaliação da divisão e conteúdo das tarefas, normas, controles e ritmos de trabalho. Em média, como pode ser observado na Tabela 3 , trabalhadores 


\begin{tabular}{|c|c|c|c|c|c|c|}
\hline \multirow[b]{2}{*}{ Variável } & \multicolumn{2}{|c|}{$\begin{array}{l}\text { Organização do } \\
\text { Trabalho }\end{array}$} & \multicolumn{2}{|c|}{$\begin{array}{c}\text { Relações } \\
\text { Socioprofissionais }\end{array}$} & \multicolumn{2}{|c|}{$\begin{array}{l}\text { Condições de } \\
\text { Trabalho }\end{array}$} \\
\hline & Média & DP & Média & DP & Média & DP \\
\hline \multicolumn{7}{|l|}{ Sexo } \\
\hline Feminino & 3,28 & 0,62 & 2,43 & 0,77 & 2,04 & 0,85 \\
\hline Masculino & 3,22 & 0,64 & 2,53 & 0,83 & 2,13 & 0,86 \\
\hline \multicolumn{7}{|l|}{ Escolaridade } \\
\hline $2^{\circ}$ grau completo & 2,94 & 0,72 & 2,31 & 0,97 & 2,39 & 1,27 \\
\hline Superior completo & 3,21 & 0,58 & 2,4 & 0,79 & 2,11 & 0,87 \\
\hline Pós-graduação & 3,29 & 0,64 & 2,51 & 0,77 & 2,03 & 0,8 \\
\hline \multicolumn{7}{|l|}{ Estado Civil } \\
\hline Solteiro (a) & 3,21 & 0,61 & 2,43 & 0,81 & 2,08 & 0,83 \\
\hline Casado (a) & 3,25 & 0,62 & 2,48 & 0,77 & 2,05 & 0,84 \\
\hline União Estável & 3,34 & 0,79 & 2,55 & 0,96 & 2,3 & 1,07 \\
\hline Viúvo (a) & 3,27 & 0,51 & 2,2 & 1,13 & 1,7 & 0,84 \\
\hline Divorciado (a) & 3,38 & 0,66 & 2,45 & 0,85 & 2,17 & 0,94 \\
\hline \multicolumn{7}{|l|}{ Faixa Etária } \\
\hline 21 a 30 anos & 3,29 & 0,62 & 2,47 & 0,77 & 2,02 & 0,75 \\
\hline 31 a 40 anos & 3,35 & 0,65 & 2,57 & 0,85 & 2,03 & 0,93 \\
\hline 41 a 50 anos & 3,16 & 0,58 & 2,38 & 0,71 & 2,09 & 0,78 \\
\hline 51 a 60 anos & 3,22 & 0,7 & 2,47 & 0,83 & 2,28 & 0,96 \\
\hline Acima de 60 anos & 2,9 & 1,03 & 1,6 & 0,79 & 1,36 & 0,37 \\
\hline \multicolumn{7}{|c|}{ Tempo de serviço na lotação } \\
\hline Até 1 ano & 3,14 & 0,52 & 2,29 & 0,69 & 2,1 & 0,75 \\
\hline 5 a 10 anos & 3,41 & 0,68 & 2,7 & 0,83 & 2,01 & 0,82 \\
\hline 6 a 10 anos & 3,33 & 0,6 & 2,47 & 0,77 & 1,99 & 0,91 \\
\hline 11 a 15 anos & 3,15 & 0,63 & 2,51 & 0,86 & 2,11 & 0,92 \\
\hline 16 a 20 anos & 3,17 & 0,73 & 2,39 & 0,86 & 2,04 & 0,85 \\
\hline 21 a 25 anos & 3,21 & 0,48 & 2,35 & 0,6 & 2,16 & 0,84 \\
\hline 26 a 30 anos & 3,16 & 0,65 & 2,34 & 0,87 & 2,46 & 1,01 \\
\hline Acima de 30 anos & 3,29 & 0,65 & 2,6 & 0,76 & 2,15 & 0,79 \\
\hline \multicolumn{7}{|c|}{ Tempo de serviço no cargo } \\
\hline Até 1 ano & 3,21 & 0,55 & 2,37 & 0,72 & 2,01 & 0,79 \\
\hline 5 a 10 anos & 3,37 & 0,65 & 2,68 & 0,87 & 2,06 & 0,88 \\
\hline 6 a 10 anos & 3,24 & 0,62 & 2,29 & 0,65 & 1,97 & 0,77 \\
\hline 11 a 15 anos & 3,07 & 0,68 & 2,38 & 0,86 & 2,05 & 1,00 \\
\hline 16 a 20 anos & 3,23 & 0,71 & 2,48 & 0,87 & 2,13 & 0,84 \\
\hline 21 a 25 anos & 3,15 & 0,45 & 2,31 & 0,49 & 2,27 & 0,92 \\
\hline 26 a 30 anos & 3,08 & 0,75 & 2,74 & 0,86 & 2,63 & 1,09 \\
\hline Acima de 30 anos & 3,77 & 0,32 & 2,8 & 1,13 & 2,55 & 0,91 \\
\hline \multicolumn{7}{|c|}{$\begin{array}{l}\text { Afastamento por motivo de saúde } \\
\text { relacionado ao trabalho }\end{array}$} \\
\hline Nenhum & 3,14 & 0,55 & 2,32 & 0,74 & 1,91 & 0,73 \\
\hline Entre 1 e 3 & 3,40 & 0,68 & 2,65 & 0,75 & 2,22 & 0,90 \\
\hline Mais de 3 & 3,50 & 0,73 & 2,82 & 0,99 & 2,66 & 1,03 \\
\hline
\end{tabular}

com pós-graduação relataram uma percepção mais crítica da organização do trabalho.

Para o tempo de serviço no cargo, de acordo com os resultados da ANOVA, há diferença significativa na percepção das relações socioprofissionais $[\mathrm{F}(7,381)=2,089 ; \mathrm{p}=0,044]$. Participantes com tempo no cargo distintos têm avaliações diferentes acerca dos modos de gestão do trabalho, comunicação e interação profissional. Em média, os trabalhadores com tempo de serviço no cargo acima de 30 anos tiveram uma avaliação negativa, grave das relações socioprofissionais.

Ao testar a diferença entre os três grupos de afastamento por motivo de saúde relacionado ao trabalho, verificou-se que há diferença significativa nos fatores organização do trabalho $[\mathrm{F}(2$, 
$381)=10,466 ; p=0,0003]$ e relações socioprofissionais $[F(2,381)=11,188 ; p=0,0001]$. Em média, participantes que se afastaram mais de três vezes percebem de forma mais crítica a divisão e o conteúdo das tarefas, as normas, os controles e os ritmos de trabalho relativos à organização do trabalho e os modos de gestão do trabalho, comunicação e interação profissional que dizem respeito às relações socioprofissionais.

\section{Custo Humano no Trabalho}

A Escala de Custo Humano no Trabalho (ECHT) é composta pelos fatores: custo físico, custo cognitivo e custo afetivo. A Tabela 4 apresenta as médias, os desvios-padrão e a variância de cada um dos fatores no estudo realizado.

A avaliação dos trabalhadores para o fator Custo Cognitivo é de "moderada a crítica" (M $=3,54 ; \mathrm{DP}=0,84 ;$ Variância $=0,91)$. Cinco dos itens que o representam foram avaliados como "negativos e graves", sendo eles: "ter que resolver problemas", "usar a visão de forma contínua”, "usar a memória", "fazer esforço mental", "ter concentração mental”.

O Custo afetivo teve uma avaliação "moderada a crítica” $(\mathrm{M}=2,44 ; \mathrm{DP}=0,83$; Variância $=0,91)$. Este fator possui dois itens que apresentaram médias acima de 3, configurando-se como avaliação mais negativa, grave : "Ter custo emocional" ( $\mathrm{M}=3,02)$ e "Ter controle das emoções” $(M=3,4)$. O fator Custo Afetivo inclui itens como: "ter controle das emoções", "ter que lidar com ordens contraditórias", "ter custo emocional", "ser obrigado a lidar com a agressividade dos outros". É importante ressaltar que os itens referentes à questão moral - "ser obrigado a elogiar as pessoas", "transgredir valores éticos" e "ser submetido a constrangimentos" - foram avaliados como satisfatórios.

O custo físico foi avaliado como satisfatório $(\mathrm{M}=2,01 ; \mathrm{DP}=0,69$; Variância $=0,83)$ o que indica que há pouco dispêndio fisiológico e biomecânico imposto ao trabalhador pelas caracte-

Tabela 4. Fatores da Escala de Custo Humano no Trabalho.

\begin{tabular}{lccc}
\hline \multicolumn{1}{c}{ Fator } & Média & DP & Variância \\
\hline Custo Cognitivo & 3,54 & 0,84 & 0,91 \\
Custo Afetivo & 2,44 & 0,83 & 0,91 \\
Custo Físico & 2,01 & 0,69 & 0,83 \\
\hline
\end{tabular}

rísticas do trabalho. Esse fator inclui itens como: "usar a força física” "usar os braços de forma contínua”, "ficar em posição curvada”, “caminhar”.

Assim como na avaliação do contexto de trabalho, os valores de variância dos fatores da ECHT mostram pouca dispersão em torno da média.

Os resultados descritivos de média e desvio -padrão dos fatores da ECHT divididos pelas variáveis sociodemográficas do estudo são apresentados na Tabela 5.

A análise de variância de um fator mostrou que não há diferenças significativas entre sexo, estado civil e tempo de serviço na lotação na avaliação dos fatores da ECHT. Em linhas gerais, quando comparadas as médias das variáveis sociodemográficas citadas, os participantes do estudo apresentam percepções similares do custo humano que é despendido no trabalho.

Com relação à escolaridade, houve diferença significativa de percepção no fator custo cognitivo $[\mathrm{F}(2,381)=6,570 ; \mathrm{p}=0,002]$. Neste fator, os participantes da pesquisa, dependendo da sua escolaridade, diferem quanto à avaliação do dispêndio intelectual para aprendizagem, resolução de problemas e tomada de decisão no trabalho. Em média, os participantes com pós-graduação relataram uma percepção mais crítica do custo cognitivo.

A comparação das médias dos grupos de faixa-etária mostrou que há diferença significativa, também, na avaliação do fator custo cognitivo $[\mathrm{F}(4,381)=3,513 ; \mathrm{p}=0,008]$. Os participantes da pesquisa com idades entre 21 e 30 anos avaliaram de forma mais negativa e grave o dispêndio intelectual.

Para o tempo de serviço no cargo, de acordo com os resultados da ANOVA, há diferença significativa na percepção do custo afetivo $[\mathrm{F}(7,381)$ $=3,116 ; \mathrm{p}=0,003]$ e do custo cognitivo $[\mathrm{F}(7$, $381)=2,540 ; p=0,015]$. Nesses fatores, os participantes com tempos distintos de serviço no cargo têm avaliações diferentes acerca dos dispêndios emocional e intelectual. Em média, os trabalhadores com tempo de serviço no cargo acima de 30 anos tiveram uma avaliação mais negativa do custo cognitivo e uma avaliação moderada do custo emocional.

Ao testar a diferença entre os três grupos de afastamento por motivo de saúde relacionado ao trabalho, verificou-se que há diferença significativa nos fatores custo afetivo $[\mathrm{F}(2,381)=3,670$; $\mathrm{p}=0,026]$ e custo físico $[\mathrm{F}(2,381)=5,027 ; \mathrm{p}=$ 0,007]. Em média, participantes que se afastaram mais de três vezes percebem de forma mais críti- 


\begin{tabular}{|c|c|c|c|c|c|c|}
\hline \multirow[b]{2}{*}{ Variável } & \multicolumn{2}{|c|}{ Custo cognitivo } & \multicolumn{2}{|c|}{ Custo afetivo } & \multicolumn{2}{|c|}{ Custo físico } \\
\hline & Média & DP & Média & DP & Média & DP \\
\hline \multicolumn{7}{|l|}{ Sexo } \\
\hline Feminino & 3,57 & 0,84 & 2,47 & 0,85 & 2,02 & 0,71 \\
\hline Masculino & 3,50 & 0,85 & 2,41 & 0,82 & 2,01 & 0,66 \\
\hline \multicolumn{7}{|l|}{ Escolaridade } \\
\hline $2^{\circ}$ grau completo & 2,95 & 0,82 & 2,13 & 0,89 & 1,94 & 0,52 \\
\hline Superior completo & 3,46 & 0,82 & 2,38 & 0,82 & 1,99 & 0,58 \\
\hline Pós-graduação & 3,63 & 0,83 & 2,50 & 0,83 & 2,03 & 0,75 \\
\hline \multicolumn{7}{|l|}{ Estado Civil } \\
\hline Solteiro (a) & 3,59 & 0,80 & 2,43 & 0,82 & 1,94 & 0,60 \\
\hline Casado (a) & 3,52 & 0,86 & 2,44 & 0,83 & 2,00 & 0,71 \\
\hline União Estável & 3,58 & 0,75 & 2,39 & 1,08 & 2,07 & 0,57 \\
\hline Viúvo (a) & 3,45 & 1,20 & 2,50 & 0,82 & 2,15 & 0,63 \\
\hline Divorciado (a) & 3,53 & 0,86 & 2,58 & 0,86 & 2,36 & 0,85 \\
\hline \multicolumn{7}{|l|}{ Faixa Etária } \\
\hline 21 a 30 anos & 3,73 & 0,75 & 2,51 & 0,84 & 1,93 & 0,64 \\
\hline 31 a 40 anos & 3,53 & 0,89 & 2,47 & 0,91 & 1,99 & 0,65 \\
\hline 41 a 50 anos & 3,59 & 0,81 & 2,43 & 0,77 & 2,12 & 0,76 \\
\hline 51 a 60 anos & 3,16 & 0,79 & 2,35 & 0,79 & 1,95 & 0,67 \\
\hline Acima de 60 anos & 3,30 & 1,13 & 1,86 & 0,83 & 1,56 & 0,31 \\
\hline \multicolumn{7}{|c|}{ Tempo de serviço na lotação } \\
\hline Até 1 ano & 3,51 & 0,82 & 2,28 & 0,64 & 1,93 & 0,57 \\
\hline 5 a 10 anos & 3,68 & 0,81 & 2,66 & 0,95 & 1,97 & 0,64 \\
\hline 6 a 10 anos & 3,62 & 0,82 & 2,41 & 0,84 & 1,86 & 0,60 \\
\hline 11 a 15 anos & 3,63 & 0,90 & 2,43 & 0,86 & 2,18 & 0,78 \\
\hline 16 a 20 anos & 3,38 & 0,82 & 2,44 & 0,83 & 2,07 & 0,80 \\
\hline 21 a 25 anos & 3,55 & 0,75 & 2,30 & 0,76 & 2,13 & 0,66 \\
\hline 26 a 30 anos & 2,99 & 0,91 & 2,29 & 0,68 & 2,36 & 0,99 \\
\hline Acima de 30 anos & 3,17 & 1,48 & 2,31 & 1,13 & 2,20 & 0,82 \\
\hline \multicolumn{7}{|c|}{ Tempo de serviço no cargo } \\
\hline Até 1 ano & 3,58 & 0,82 & 2,31 & 0,72 & 1,92 & 0,63 \\
\hline 5 a 10 anos & 3,65 & 0,78 & 2,69 & 0,92 & 1,98 & 0,67 \\
\hline 6 a 10 anos & 3,63 & 0,88 & 2,30 & 0,74 & 1,99 & 0,61 \\
\hline 11 a 15 anos & 3,42 & 0,93 & 2,38 & 0,85 & 2,19 & 0,85 \\
\hline 16 a 20 anos & 3,45 & 0,85 & 2,49 & 0,90 & 2,14 & 0,81 \\
\hline 21 a 25 anos & 3,25 & 0,61 & 2,05 & 0,57 & 2,02 & 0,58 \\
\hline 26 a 30 anos & 2,67 & 0,97 & 2,15 & 0,84 & 2,12 & 0,87 \\
\hline Acima de 30 anos & 4,30 & 0,28 & 3,25 & 0,58 & 2,80 & 0,71 \\
\hline \multicolumn{7}{|c|}{$\begin{array}{l}\text { Afastamento por motivo de saúde } \\
\text { relacionado ao trabalho }\end{array}$} \\
\hline Nenhum & 3,51 & 0,79 & 2,36 & 0,78 & 1,93 & 0,61 \\
\hline Entre 1 e 3 & 3,64 & 0,95 & 2,54 & 0,87 & 2,13 & 0,81 \\
\hline Mais de 3 & 3,43 & 0,78 & 2,68 & 0,98 & 2,21 & 0,71 \\
\hline
\end{tabular}

ca o dispêndio emocional. O custo físico ainda se encontra na faixa da avaliação mais positiva.

\section{Discussão}

A análise dos resultados obtidos evidencia que o fator condições de trabalho foi avaliado positivamente e que os fatores organização do trabalho e relações socioprofissionais da escala de contexto de trabalho foram avaliados de forma negativa, indicando risco de adoecimento para esses trabalhadores. É provável que o ritmo e o modelo gestão do trabalho e as interações profissionais, da forma como estão postos, gerem, no trabalhador, um elevado custo cognitivo e afetivo para execução das atividades.

$\mathrm{Na}$ organização do trabalho, fatores como as divisões de tarefas, a estrutura hierárquica, os tempos de trabalho, os ritmos, as cadências do 
serviço, os critérios de qualidade e de produtividade $^{34}$ influenciam a avaliação dos trabalhadores que, no estudo, foi negativa. Especificamente, os participantes com pós-graduação e os que se afastaram mais de três vezes avaliaram de forma mais crítica. Uma hipótese para a avaliação negativa da organização do trabalho é a sobrecarga de tarefas e as mudanças ocorridas devido à reforma e modernização do Judiciário ${ }^{8,9}$. Além disso, os trabalhadores que já se afastaram mais de três vezes por motivo de saúde relacionado ao trabalho devem ter desenvolvido uma imagem mais negativa do órgão e do trabalho que realizam, visto que as vivências e mal-estar no trabalho estão em evidência.

No que diz respeito às relações socioprofissionais, de forma global, os participantes da pesquisa relataram uma percepção crítica delas dentro do órgão. Dentre os participantes, os que possuem mais tempo de serviço no cargo e os que se afastaram mais de três vezes foram os que pior avaliaram esse fator. Segundo Zanelli et al. ${ }^{35}$, o contexto influencia as emoções, o humor e o afeto do trabalhador, o que pode facilitar ou dificultar as interações sociais e o desenvolvimento de um clima propício ao bem-estar do trabalho. Possivelmente, as dificuldades enfrentadas por conta de uma organização do trabalho aquém das necessidades dos trabalhadores estão impactando negativamente as interações hierárquicas e entre pares.

Os resultados da escala de custo humano no trabalho sinalizam o que é despendido pelos trabalhadores para dar conta das exigências de tare$\mathrm{fas}^{22}$. O custo físico foi avaliado positivamente. Já o custo cognitivo e o custo afetivo foram avaliados de forma crítica pelos participantes na análise descritiva e nas categorias faixa-etária, escolaridade, tempo de serviço no cargo e afastamento. Tais dados indicam um alto dispêndio mental e emocional para responder às exigências do trabalho e que categorias estão sendo mais atingidas. Conforme destaca Anchieta et al. ${ }^{30}$, o custo humano relativamente alto pode gerar problemas a longo prazo. Ademais, explicita a discrepância que existe entre o trabalho prescrito pelos modelos de gestão e as situações reais de trabalho ${ }^{1-3,22}$.

Comparando os resultados deste estudo com as pesquisas apresentadas anteriormente, nota-se que, assim como no trabalho dos digitadores ${ }^{26}$, dos carteiros $^{27}$, dos bancários ${ }^{28}$, dos policiais ${ }^{30} \mathrm{e}$ dos profissionais da saúde ${ }^{31}$, há uma coexistência entre vivências de bem-estar e mal-estar no trabalho e que a sua organização é o fator mais crítico nesses contextos. Pode-se inferir que os modos de lidar com as contradições típicas das situações reais de trabalho, ou seja, as estratégias de mediação permitem ao trabalhador dar conta do real das tarefas sem adoecer. Entretanto, elas podem falhar devido ao elevado nível de exigência.

Globalmente, os resultados encontrados não indicam problemas graves relacionados à saúde dos trabalhadores do órgão pesquisado. Entretanto, os fatores organização do trabalho e custo cognitivo merecem atenção devido às avaliações mais graves. A análise aprofundada dessas duas dimensões pode desvelar fontes de mal-estar no trabalho. Conforme preconiza a Ergonomia da Atividade, para lidar com o custo humano do trabalho, os trabalhadores desenvolvem estratégias de mediação individuais e coletivas. Caso essas estratégias sejam ineficazes, os trabalhadores podem vivenciar sofrimento e, até mesmo adoecer. Anchieta et al. ${ }^{30}$ sinalizam que as estratégias de mediação devem ser trabalhadas para que haja diminuição do risco de adoecimento. Além disso, é necessária a compreensão da situação de trabalho com vistas a transformá-la.

A utilização do ITRA permitiu o alcance do objetivo do estudo: avaliar o contexto de trabalho e seu custo humano em um órgão do Poder Judiciário brasileiro; e o mapeamento de indicadores críticos relacionados ao trabalho dos participantes da pesquisa. Os resultados servem de subsídio para intervenções que promovam mudanças no contexto de trabalho e para elaboração de uma agenda de estudos longitudinais que permitam o acompanhamento das percepções dos trabalhadores com o passar do tempo.

Este estudo apresenta limitações, pois se baseou em autorrelato, foi realizado com uma amostra pequena se comparado ao total de trabalhadores. Os estagiários e terceirizados não participaram e, por meio do ITRA, não é possível identificar as estratégias de mediação. Portanto, pesquisas futuras podem se focar no mapeamento das estratégias de mediação individuais e coletivas e os impactos dessas estratégias nas vivências de bem-estar e mal-estar no trabalho.

\section{Colaboradores}

CS Antloga trabalhou na concepção da pesquisa e do artigo e na redação do artigo. M Maia, KR Cunha e J Peixoto trabalharam na pesquisa e na redação do artigo. 


\section{Referências}

1. Guida HFS, Brito J, Alvarez D. Gestão do trabalho, saúde e segurança dos trabalhadores de termelétricas: um olhar sob o ponto de vista da atividade. Cien Saude Colet 2013; 18(11):3125-3136.

2. Pessanha EGF, Artur K. Direitos trabalhistas e organização dos trabalhadores num contexto de mudanças no mundo do trabalho: efeitos sobre os trabalhadores da saúde. Cien Saude Colet 2013; 16(8):3373-3382.

3. Feliciano KVO, Kovacs MH, Sarinho SW. Burnout entre médicos da Saúde da Família: os desafios da transformação do trabalho. Cien Saude Colet 2011; 18(6):1569-1580.

4. Baumgarten M. Tecnologias sociais e inovação social. In: Cattani AD, Holzmann L, organizadores. Dicionário de trabalho e tecnologia. Porto Alegre: Editora da UFRGS; 2006. p. 302-304.

5. Holzmann L. Novas tecnologias. In: Cattani AD, Holzmann L, organizadores. Dicionário de trabalho e tecnologia. Porto Alegre: Editora da UFRGS; 2006. p. 189-191.

6. Rebecchi E. O sujeito frente à inovação tecnológica. Petrópolis: Vozes; 1990.

7. Faria JH. Tecnologia e processo de trabalho. Curitiba: Editora da UFPR; 1992.

8. Andrade PP. Sentimento de (In)justiça na Justiça: fatores (des)estruturantes de QVT sob a ótica dos servidores de um órgão do Poder Judiciário [dissertação]. Brasília: Universidade de Brasília; 2011.

9. Fernandes LC. "Estamos o tempo todo enxugando gelo": Qualidade de vida no trabalho e vivências de bem-estar e mal-estar em um órgão do poder judiciário [dissertação]. Brasília: Universidade de Brasília; 2013.

10. Jorge SM. A qualidade de vida no trabalho: Um estudo junto aos servidores públicos da Subseção Judiciária Federal de Campinas/SP [dissertação]. Piracicaba: Universidade Metodista de Piracicaba; 2009.

11. Moraes A. Direito Constitucional. São Paulo: Atlas; 2006.

12. Costa NN, Alves GM. Constituição Federal anotada e explicada. Rio de Janeiro: Forense; 2005.

13. Tavares DS. O sofrimento no trabalho entre servidores públicos: Uma análise psicossocial do contexto de trabatho em um tribunal judiciário federal [dissertação]. São Paulo: Universidade de São Paulo; 2003.

14. Sadek MT, Arantes RB. A crise do Judiciário e a visão dos juízes. Revista USP 1994; 21:34-45.

15. Cintra DAD JR. Reforma do Judiciário: Não pode haver ilusão. Estud. av. 2004; 18(51):169-180.

16. Brasil. Emenda Constitucional no 45 de 30 de dezembro de 2004. Altera dispositivos dos arts. 5०, 36, 52, 92, 93, 95, $98,99,102,103,104,105,107,109,111,112,114,115$, $125,126,127,128,129,134$ e 168 da Constituição Federal, e acrescenta os arts. 103-A, 103B, 111-A e 130-A, e dá outras providências. Diário Oficial da União 2004; $31 \mathrm{dez}$.

17. Ferro MVG. Um estudo sobre a motivação dos servidores da Justiça Federal em Fortaleza à luz da teoria dos fatores higiênicos e motivacionais de Frederick Herzberg [monografia]. Fortaleza: Universidade Estadual Vale do Acaraú; 2008.

18. Wirth MFP. Vivências de prazer e sofrimento de gestores de um órgão do poder judiciário federal [monografia]. Brasília: Universidade de Brasília; 2008.

19. Moura JT. Mudanças estruturais e administrativas e vivências de prazer e sofrimento no trabalho no âmbito da coordenadoria de taquigrafia de uma organização do Poder Judiciário federal [monografia]. Brasília: Universidade de Brasília; 2009.
20. Wisner A. Por dentro do trabalho - Ergonomia: Método e Técnica. São Paulo: FTD; 1987.

21. Ferreira MC, Mendes AM. Trabalho e Riscos de adoecimento: O caso de auditores-fiscais da Previdência Social brasileira. Brasília: LPA; 2003.

22. Ferreira MC. Qualidade de Vida no Trabalho: uma abordagem centrada no olhar dos trabalhadores. $2^{\mathrm{a}}$ ed. Brasília: Paralelo 15; 2012.

23. Oliveira PAB. Cargas de trabalho e seu impacto sobre a saúde: estudo de caso em quatro instituições financeiras em Porto Alegre. Bol. Saúde 2005; 19(1):69-92.

24. Lima HKB. Gestão de Pessoas e Qualidade de Vida no Trabalho no Contexto do Poder Legislativo do Distrito Federal [dissertação]. Brasília (DF): Universidade de Brasília; 2008.

25. Mendes AM. Psicodinâmica do Trabalho: Teoria, Método e Pesquisa. Brasília: Casa do Psicólogo; 2007.

26. Rego VB, Vieira AP, Pereira JAS, Facas EP. O trabalho dos digitadores terceirizados de uma instituição bancária pública. In: Mendes AM, organizadora. Psicodinâmica do Trabalho: teoria, método e pesquisas. São Paulo: Casa do Psicólogo; 2007. p. 303-324.

27. Rossi EZ, Calgaro JCC, Melo VS. O trabalho dos carteiros no manuseio e na entrega de correspondências. In: Mendes AM, organizadora. Psicodinâmica do Trabalho: teoria, método e pesquisas. São Paulo: Casa do Psicólogo; 2007. p. 325-343.

28. Sousa CM, Ferreira JB, Castro-Silva LM, Martins MV. O trabalho dos bancários em instituição financeira pública. In: Mendes AM, organizadora. Psicodinâmica do Trabalho: teoria, método e pesquisas. São Paulo: Casa do Psicólogo; 2007. p. 345-359.

29. Silva RR. O trabalho de líderes religiosos em organizações protestantes neopentecostal e tradicional. In: Mendes AM, organizadora. Psicodinâmica do Trabalho: teoria, método e pesquisas. São Paulo: Casa do Psicólogo; 2007. p. 283-301.

30. Anchieta VCC, Galinkin AL, Mendes AM, Neiva ER. Trabalho e Riscos de Adoecimento: Um Estudo entre Policiais Civis. Psicologia: Teoria e Pesquisa. 2011; 27(2):199-208.

31. Shimizu HE, Carvalho Júnior DAC. O processo de trabalho na Estratégia Saúde da Família e suas repercussões no processo saúde-doença. Cien Saude Colet 2012; 17(9):2405-2414.

32. Mendes AM, Ferreira MC. Inventário sobre Trabalho e Riscos de adoecimento - ITRA: Instrumento de indicadores críticos no trabalho. In: Mendes AM, organizadora. Psicodinâmica do Trabalho: teoria, método e pesquisas. São Paulo: Casa do Psicólogo; 2007. p. 111-128.

33. Ferreira MC, Facas EP, Vieira AP. Validação do Inventário de Trabalho e Riscos de Adoecimento - ITRA. Trabalho apresentado no IV Congresso de Psicologia NorteNordeste. Salvador (BA); 2005, Mai 25-28.

34. Abrahão J, Sznelwar L, Silvino A, Sarmet M, Pinho D. Introdução à Ergonomia da prática à teoria. São Paulo: Editora Blucher; 2009.

35. Zanelli JC, Borges-Andrade JE, Bastos AV. Psicologia, Organizações e Trabalho no Brasil. Porto Alegre: Artmed; 2004.

Artigo apresentado em 30/09/2013

Aprovado em 23/10/2013

Versão final apresentada em 31/10/2013 